\title{
PROGRESS IN CANCER RESEARCH
}

$T$ HE Seventh International Cancer Congress, organized by the International Union against Cancer, was held in London during July 6-12 under the presidency of Sir Stanford Cade. A meeting involving about 600 papers and 2,500 members is not easy to survey: as was to be expected, nothing dramatic emerged and in these circumstances it is almost impossible to judge where the most significant advances are in fact being made. Specialists in the many disciplines embraced by cancer research would all have differing ideas on this, and a short review of the proceedings must therefore be a biased one.

\section{Hormones}

O. Mülhbock (Holland) expressed the view that cancer induced by hormones is always the result of super-normal production of a growth-stimulating hormone and that hormonal deficiency never gives rise to neoplasia. Mülhbock and his co-workers have shown that breast carcinoma can be induced in mice free from the milk factor by the repeated implantation of pituitary glands from mice of the same strain. A. Lipschutz (Chile) described the occurrence of an ovarian neoplasm (luteoma) following sub-total castration. This is possibly another instance of pituitary over-stimulation. R. E. Kavetsky and his colleagues (U.S.S.R.) provided evidence that disturbance of the rhythm of activity of the pituitary gonadotropic and mammatropic hormones was a feature of high-cancer strains of mice. Another example is that described by J. Bielschowsky (New Zealand) in the case of thyroid tumours, the genesis of which is dependent on continuous over-stimulation by the pituitary thyrotropic hormone. The tumour itself may continue to be dependent on the same hormonal stimulation. This property has been utilized in treatment in man, since by administering a goitrogen the tumour can be induced to secrete thyroxin and thus become vulnerable to radioactive iodine.

One has the general impression that the relation between hormonal stimulation and cancer is being clarified rapidly and its role in the genesis of human tumours, particular of the breast, may prove important. The mechanism is still little understood, but the knowledge that certain tumours of tissues responsive to sex-hormones may still be dependent on such hormones has resulted in a significant therapeutic advance. C. Huggins (United States), who has notable achievements in this field to his credit, reviewed the treatment of cancer of the breast by surgical removal of the ovaries and the adrenal and pituitary glands. Both he and H. Shay (United States) described useful and rapid methods of inducing cancer in the breast of rats by intensive but limited oral treatment with methylcholanthrene.

\section{Metabolism of Carcinogens}

The fate of injected chemical carcinogens with its corollary, the mechanism of carcinogenesis, was a dominant topic. I. Berenblum (Israel) reviewed this subject and suggested that with the polycyclic hydrocarbons there is still no firm evidence on whether the carcinogen itself or a metabolite is the decisive factor. On the other hand, C. Heidelberger (United States) argued that carcinogenic activity is correlated directly with specific protein-binding as a first step leading eventually to the deletion of the essential enzymes regulating cell-growth. He gave evidence that the binding is in the $K$ region first described by the Pullmans. A. Pullman (France) described his electronic theory and urged greater co-operation on the biological side which will be necessary to test its validity. The theory demands protein-binding with the carcinogen and not with a metabolite.

H. R. Gutmann (United States) showed that an ortho-hydroxyamine derivative from 2-acetylaminofluorene is capable of protein-binding in simple biochemical systems. Specific protein-binding as the primary process in carcinogenesis is an exceedingly important concept and, though not mentioned extensively at the Congress, its implications in the immunological approach to cancer were stressed by H. N. Green (Great Britain) and others.

The metabolism of the carcinogenic aromatic amines is largely linked up with studies on bladder cancer. G. M. Bonser (Great Britain) described the pioneer work by which she and her colleagues had shown that 2-naphthylamine is carcinogenic to the bladder of dog and man by virtue of its conversion to 2 -amino- $l$-naphthol. The evidence that ortho-hydroxy amines are of importance in amine carcinogenesis in general was amplified by D. B. Clayson (Great Britain) and L. Bradshaw (Great Britain) in relation to the metabolic fate of benzidine and 4-aminodiphenyl.

E. Boyland (Great Britain) suggested that carcinogenic metabolites may be liberated in the bladder by the action on the ortho-amino phenol conjugates (formed in the liver) of the enzymes glucuronidase and phosphatase. He described carcinogenic orthoaminophenols (for example, 3-hydroxyanthranilic acid) which are products of tryptophan metabolism and so may be endogenous carcinogens. Since urinary $\beta$-glucuronidase is inhibited by oral administration of $1: 4$-glucosaccharolactone, the possibility of preventing bladder cancer arises.

\section{lonizing Radiations}

Interest in ionizing radiations was mainly focused on the carcinogenic hazard in man and the induction of tumours in mice. R. Doll (Great Britain) described the definite but low incidence of leukæmias induced by $\mathrm{X}$-rays in man and the evidence supporting somatic mutation as the cause. A. M. Brues (United States) opposed this view, because the evidence also suggests that the risk of carcinogenesis increases disproportionately to the dosage.

One of the many interesting ways of inducing cancer by irradiation was described by $\mathbf{P}$. Furth (United States) who, by irradiating the pituitary gland, produced tumours which were functional and thus induced tumours in other conditioned target organs. L. W. Law (United States) described malignant lymphomas in mice given homologous or semiisologous bone marrow as a protection against lethal irradiation. H. S. Kaplan (United States) argued that carcinogenic agents may act indirectly since thymic leukæmias occur in the unirradiated thymus grafted into thymectomized mice subjected to prior irradiation. N. Petrov (U.S.S.R.) and his co-workers described the production of tumours in the bones of apes by the local action of radioactive minerals, an effect not obtained with carcinogenic hydrocarbons. 


\section{Viruses}

Tumour viruses were widely discussed, but the outstanding interest was in the leukæmia viruses of mice. L. Gross (United States) discussed his work on the induction of leukæmia and parotid tumours with cellfree extracts of leukæmia tissues given to new-born mice. C. Friend (United States) described similar extracts rapidly inducing leukrmia in adult mice, while T. Latarjet (France) dealt with cell-free extracts - and deoxyribonucleic and ribonucleic acids derived from them-accelerating the onset of leukæmia and inducing the appearance of other tumours. These and other important contributions have great theoretical interest. Their relation to human leukæmias is doubtful, and indeed Sir Macfarlane Burnet rather disturbed the cancer virus experts by his categorical declaration on epidemiological grounds that viruses played no part in the etiology of solid tumours in man.

\section{Immunology and Immunogenetics}

There were signs of a mounting interest in the field of immunology and immunogenetics not only in the number of directly relevant papers submitted but also in the references to immunological approaches in many others. H. N. Green (Great Britain) described his immunological theory, which ascribes the neoplas. tic state to absence of tissue-specific immunological identity in the cell. Evidence was presented that a specific antigenic complex is formed by carcinogen binding probably with a lipo-protein complex which, possibly as a result of an immune reaction, results in the emergence of a strain of cells lacking such a complex. E. Weiler (United States) has previously found a loss of tissue-specific antigens in chemically induced tumours of the liver and kidney and, by ingenious isotopic and immune techniques, has now demonstrated their loss in the second generation of normal kidney epithelium tissue culture. The failure to induce chemical carcinogenesis, contrasted with the occurrence of malignant transformation in tissue culture, was one of the many facts presented originally in support of Green's theory. C. A. Zilber (U.S.S.R.), as well as G. P. Cunningham and his co-workers (Great Britain), indicated that an antigenic complex is formed in chernical carcinogenesis of the liver. Zilber found that this disappears, to be replaced in the tumour by a specific antigen with no carcinogen specificity. Tumour antigens are found in human and virus tumours. Antigenic change in tumours is both quantitative and qualitative.

Sir Macfarlane Burnet, in a broad survey of the biological nature of cancer, concluded that it can best be explained on a basis of somatic mutation and clone selection. The problem is to find whether these mutations are due to random action of many kinds of stimuli, deviation of some process of cellular differentiation or enforced and directed mutation by the action of specific substances. The auto-immune state is not excluded as a cause, but more experimental support is needed. G. Klein (Sweden) suggested that the evolution of the neoplastic cell towards greater autonomy is due to intercellular variation followed by selection. L. Sachs (Israel) demonstrated that though greater freedom of transplantability may involve loss of agglutinogens it always implies greater antigenicity in general, a finding which is by no means opposed to an immunological theory of loss of cytoplasmic specific antigens.

Immunological ideas are being increasingly used in experimental therapy, for example, in tagging radioiodine on to tissue-specific antibody globulin (by I. L. Spar and his co-workers in the United States).

Space does not allow of discussion of many important subjects. Naturally, the relation between smoking and cancer was a prominent topic, and half the Congress was devoted to clinical papers. These topics and the important subject of the control of cancer are of great importance, but they will be covered fully in the medical press. Chemotherapy, however, must be mentioned here, as it occupied an important part of the proceedings. Many new synthetic com. pounds were described, the present emphasis being away from the radiomimetic and towards the antimetabolic compounds. Nevertheless a large amount of work still stems from the original work of $\mathrm{A}$. Haddow and his colleagues on therapy with alkylating agents. Moreover, the great number of papers on nucleic acid metabolism and carcinogenesis reported at the Congress were derived largely from the original studies on the mechanism of action of such agents.

Even a long review could not be fair to every significant contribution. It is indeed very possible that among the hundreds not mentioned specifically some may have more potential importance than any cited here, For example, the work of $K$. Setälä and his co-workers (Finland) on the cancer-promoting activities of 'Tween 60' or of the purely physical induction of cancer by plastic films by E. T. Oppenheimer (United States) may fall within this category. The cancer scene still covers a broad canvas and the vitally important detail may not yet have been emphasized.

H. N. GREEN

\section{BRITISH RAYON RESEARCH ASSOCIATION \\ OPEN DAYS}

T HE British Rayon Research Association held the third of its annual open days during May 7-9. The total attendance was $650-700$, some 300 attending on the second day. A new technological building has been built and this houses the wool processing machinery, the work on vibration problems on spinning frames and the fluid-bed work. All the work of the Association was shown with the exception of that on fluid beds, which, as it has been moved twice in the past twelve months, was not in a suitable condition for demonstration. In order to present the fundamental work in a form which showed its relevance to problems in the textile industry, two short lectures on the work of the chemistry and physics groups were given by the senior chemist and senior physicist immediately after lunch on each day. These were well attended and well received.

Because of the disorganization caused to technological work by the vacation of the Barton Dock Road premises and the subsequent upheaval in the 